\title{
REVISÃO JUDICIAL SOB O ENFOQUE DO ORIGINALISMO E DO INTERPRETATIVISMO
}

\author{
Elísio Augusto Velloso Bastos ${ }^{1}$ \\ Márcio Alves Figueira ${ }^{2}$
}

\section{RESUMO}

$\mathrm{O}$ artigo científico visa esclarecer acerca do judicial review com enfoque no originalismo e no interpretativismo. Neste trabalho pretendemos demonstrar ser o interpretativismo um construto da Suprema Corte dos Estados Unidos oriundo do precedente Brown. Em primeiro lugar, examinaremos os precedentes da Suprema Corte, cujos fundamentos foram obtidos a partir da corrente originalista, até chegarmos ao citado caso Brown e em seguida analisaremos filosoficamente o precedente. Em conclusão, antes se buscava a intenção original do constituinte, no entanto, modernamente, almeja-se controlar a constitucionalidade com parâmetro nos princípios constitucionais.

Palavra-Chave: Judicial Review; Originalismo; Interpretativismo; Segregação Racial; EUA.

\section{JUDICIAL REVIEW FROM THE FOCUS OF ORIGINALISM AND INTERPRETATIVISM}

\begin{abstract}
The scientific article aims to clarify about the judicial review with a focus on originalism and interpretativism. In this paper, we intend to demonstrate that interpretativism is a construct of the United States Supreme Court originating from Brown precedent. First, we will examine the precedents of the Supreme Court, whose foundations were obtained from the originalist current, until we arrive at the aforementioned Brown case and then we will analyze the precedent philosophically. In conclusion, before the original intention of the constituent was sought, however, modernly, the aim is to control constitutionality with a parameter in constitutional principles.
\end{abstract}

Key words: Judicial Review; Originalism. Interpretativism; Racial Segregation; EUA.

\section{INTRODUÇÃO}

\footnotetext{
${ }^{1}$ Doutor em Direito do Estado pela faculdade de Direito da Universidade de São Paulo (USP). Professor em Direitos Humanos e em Teoria Geral da Constituição (Graduação) e em Teoria da Constituição no Centro Universitário do Estado do Pará- CESUPA. Coordenador do Grupo de Pesquisa Inteligência Artificial, Democracia e Direitos Fundamentais. Procurador do Estado do Pará. Advogado. E-mail: elisio.bastos@uol.com.br ${ }^{2}$ Mestrando em Direito e Políticas Públicas do Centro Universitário do Estado do Pará, Defensor Público do Estado do Pará. Graduado em Direito pela Fundação Universidade Federal do Amapá/AP em 1999. Especialista pela Anhanguera-Unierp em 2011. SubProcurador Jurídico da Câmara Municipal de Macapá, de 1999 a 2000. Procurador-Geral do Estado do Amapá, no ano de 2011. E-mail: df.marciofigueira@gmail.com
} 
A jurisdição constitucional pautada no pioneiro precedente Marbury versus Madison (1803), fruto da experiência constitucional estadunidense, possui como consectário lógico, a autoatribuição ao Poder Judiciário da função de controle de constitucionalidade das leis (BASTOS, 2009, p. 57).

Neste sentido, a Constituição é a lei fundamental, e os juízes devem aplicá-la (DWORKIN, 2005, p. 41).

Cabe salientar, que o precedente Marbury versus Madison (1803) consiste no primeiro caso em que a Supreme Court of the United States (SCOTUS), declarou a possibilidade de um Tribunal julgar inconstitucional uma lei oriunda do Congresso Nacional, tomando-se como parâmetro a própria Constituição (BASTOS, 2009, p. 59).

Não obstante, o controle de constitucionalidade das leis não foi uma unanimidade dos Estados Unidos da América. Tal circunstância é comprovada pelo longo lapso temporal entre Marbury versus Madison (1803) e a segunda decisão a trilhar o mesmo caminho, qual seja, o precedente Dred Scott versus Sandford (1857) (BASTOS, 2009, p. 61).

É necessário que se realize uma análise atenta envolvendo os principais precedentes oriundos do judicial review norte-americano, para demonstrar-se o método mais adequado de interpretação da própria Constituição (DWORKIN, 2007, p. 20, 25, 29, 36).

Vale enfatizar que dentro da jurisdição constitucional norte-americana fora adotado tanto a vertente originalista quanto a interpretativista, inclusive objeto dos principais precedentes oriundos da Supreme Court of the United States (SCOTUS), fazendo-se necessário uma análise aprofundada dos precedentes Marbury versus Madison (1803), Dred Scott versus Sandford (1857), Plessy versus Ferguson (1896) e Brown versus Board of Education of Topeka (1954), para se poder extrair a ratio decidendi dos precedentes.

A rigor, não existe um dispositivo constitucional explícito autorizativo do controle de constitucionalidade das leis (BASTOS, 2009, p. 60), embora se possa extrair dos precedentes supramencionados duas posturas em relação à intepretação do texto constitucional, vislumbradas como postura originalista e a interpretativista.

É essencial demonstrar que a postura originalista, enquanto corrente, afirma que a anulação da lei seria possível quando decorresse da intenção dos legisladores constituintes (DWORKIN, 2005, p. 49).

No que tange à postura interpretativista, o objetivo da revisão judicial seria oferecer uma interpretação da Constituição enquanto documento jurídico original e fundador, 
pretendendo integrar a Constituição à nossa prática constitucional e jurídica como um todo (DWORKIN, 2005, p. 45).

Sem embargo, uma premissa básica deste artigo é a naturalização do originalismo e a falha parece estar afeita justamente em tal naturalização, e na desconsideração do interpretativismo com a leitura moral da Constituição baseada em princípios.

O presente trabalho tem por objetivo demonstrar o interpretativismo como um construto da Supreme Court of the United States (SCOTUS), oriundo do precedente Brown v. Board of Education of Topeka (1954).

A discussão teórica consistirá na exposição da corrente filosófica originalista, assim como, da corrente filosófica interpretativista.

Ora, aqui também se faz necessário formular uma hipótese para esta pesquisa, com o intuito de responder, preliminarmente, ao problema científico, com este teor: o magistrado, responsável pela revisão judicial, limitado pelo teor das disposições constitucionais, não poderia adotar o originalismo como método de interpretação da própria Constituição, máxime pelo enfoque da integridade do direito.

O método adotado nesta pesquisa foi o bibliográfico, com análise dos principais precedentes oriundos da Supreme Court of the United States (SCOTUS), por meio de pesquisa bibliográfica, para alcançar o objetivo pretendido.

Este artigo está estruturado a partir da análise dos precedentes Marbury versus Madison (1803), Dred Scott versus Sandford (1857), Plessy versus Ferguson (1896) e Brown versus Board of Education of Topeka (1954), traçando uma linha evolutiva do pensamento jurídico norte-americano.

Por fim, nas considerações finais, foram discutidos os problemas envolvendo a aplicabilidade da postura originalista e interpretativista com base nos confrontos teóricos e jurídicos, tendo como fundamento os precedentes da Supreme Court of the United States (SCOTUS), concluindo-se com sugestões fruto desta pesquisa e da experiência do pesquisador.

\section{O PRECEDENTE MARBURY V. MADISON (1803)}

Primordialmente, o modelo de controle de constitucionalidade norte-americano possui a sua gênese no precedente oriundo da Supreme Court of the United States (SCOTUS), no ano de 1803, precisamente em Marbury contra Madison (BASTOS, 2009, p. 57). 
Cabe salientar, no ano de 1800, a derrota do Partido Federalista nas eleições para o Congresso Nacional e também para Presidência da República. Nestes termos, estava prevista para março de 1801, a posse do novo Presidente da República, Thomas Jefferson, ligado ao Partido Democrata Republicano (MENDES; BRANCO, 2018, p. 50).

Nada obstante, tal derrocada não representaria saída dos membros do Partido Federalista da vida pública estadunidense, por conta da aprovação da Lei do Tribunal de Circuito, de 13/02/1801, por meio da qual foram criados 16 cargos de Juiz Federal de Apelação espalhados em vários pontos do território americano; aliada a promulgação da Lei Orgânica do Distrito de Columbia, de 27/02/1801, a qual também criou 42 cargos de juiz de paz para atuarem naquele Distrito (MENDES; BRANCO, 2018, p. 50).

Há de se ver que a estratégia dos federalistas visava nomear correligionários para ocuparem os cargos recém-criados no Poder Judiciário, o que gerou uma corrida por nomeações antes do final do mandato do Presidente federalista, John Adams, com realce para William Marbury, Dennis Ramsay, Robert Townsend e William Harper, todos para os cargos de juiz de paz do Distrito de Columbia, os quais foram confirmadas pelo Congresso NorteAmericano, tendo o selo presidencial sido aposto nos termos de nomeação (MENDES; BRANCO, 2028, p. 51).

Não obstante, os termos de nomeação, por razões desconhecidas, não foram entregues aos nomeados, o que os impediria de tomar posse nos cargos de juiz de paz do Distrito de Columbia, inclusive o novo Secretário de Estado, James Madison, recusou a entregar os termos de nomeação, mesmo notificado para tanto, sustentando não haver direito aos cargos (MENDES; BRANCO, 2028, p. 51).

Nesta sequência, os requerentes diante da recusa do novo Secretário ajuizaram um mandamus perante a SCOTUS, pleiteando a entrega dos termos de nomeação para que pudessem tomar posse nos seus respectivos cargos de juiz de paz do Distrito de Columbia. Coube à relatoria do caso ao Chefe de Justiça, John Marshall, então Presidente da Suprema Corte dos Estados Unidos.

Infere-se, assim, que a abordagem da questão partiu de uma técnica processual inusitada, já que pelo voto do Chefe de Justiça, John Marshall, abordaram-se questões referentes ao direito dos requerentes a tomar posse no cargo de juiz de paz e a existência de um remédio adequado para garantir o direito violado, precedendo o julgamento acerca da competência da SCOTUS para dirimir a referida controvérsia, o que uma vez não acolhido, 
prejudicaria a análise das demais questões referentes a existência do direito ou existência de meio adequado para dirimir o litígio, constando no voto com estes termos:

[...] Na ordem respectiva pela qual a Corte examinou a matéria, as seguintes questões foram consideradas e decididas: 1 . O peticionário tem direito a tomar posse como juiz de paz? 2. Se ele tem o direito, e o direito foi violado, as leis desse país garantem a ele um remédio? 3. Se as leis garantem o remédio, será ele um mandamus proferido por essa Corte? [...] (KLAUTAU FILHO, acesso em: 4 set. 2019).

Verifique-se que a primeira indagação fora respondida afirmativamente, considerando que os requerentes teriam direito à nomeação nos cargos de juiz de paz do Distrito de Columbia, uma vez que a nomeação teria sido assinada pelo Presidente, com a inserção do selo de nomeação dos Estados Unidos, pelo Secretário de Estado.

Além disso, nesta parte do voto fica perceptível que o controle de constitucionalidade não é sustentado como pedido principal da demanda, no entanto, ele é suscitado pela via incidental, no curso do processo como medida relevante para a solução da controvérsia (BASTOS, 2009, p. 157), sendo consagrado no voto que, segundo Klautau Filho (S.D.; N.P.), decidiu que "É decididamente a opinião da Corte de que quando a nomeação é assinada pelo Presidente, a indicação é feita; e a nomeação está completa quando o selo dos Estados Unidos foi afixado a ela pelo Secretário de Estado", inferindo-se de que não é permitido negar a entrega do termo de nomeação.

Nesta seara do Modelo norte-americano, pode-se afirmar que foi resolvida a primeira questão, devendo-se, necessariamente, adentrar no segundo quesito, posto que este versava sobre: "Se ele tem o direito, e o direito foi violado, as leis desse país garantem a ele um remédio?" (KLAUTAU FILHO, S.D.; N.P.).

Ora, aqui também fora respondida afirmativamente a indagação constante no mandamus, pautado na Lei que lhe assegurou o direito de obtenção de cópia dos termos de nomeação, mediante o pagamento de dez centavos, corroborado pela tese de que a matéria não se encontrava sob sigilo e seu caráter não era discricionário para a competência de um Secretário de Estado.

Note-se que o fundamento legal da competência da SCOTUS para processar e para julgar o mandamus encontrava arrimo na Seção 13 do Ato Judiciário, de 24/09/1789, com o seguinte teor:

[...] Section 13. The Supreme Court will also have jurisdiction to appeal to the courts and tribunals of the various states, in the cases provided for herein, especially for the cases provided for, and will be empowered to issue prohibition sentences to the district courts, when they proceed as courts. admiralty and maritime jurisdiction, and writ of mandamus, in cases guaranteed by the principles and uses of the law, to any designated courts, or persons in office, under the authority of the United States [...]. 
Cabe destacar, que a Constituição dos Estados Unidos da América (CEUA), de 17/09/1787, atribui competência à Suprema Corte, no artigo III, Seção 2, de forma diversa da prevista na Seção 13 do Ato Judiciário, de 1789, já que a competência originária fixada seria restrita a Embaixadores, outros Ministros e Cônsules, bem como naquelas em que se achar envolvido um Estado, cujos termos são o seguinte:

[...] A R T I G O III [...] Section 2 [...] 2. In all matters relating to ambassadors, other ministers and consuls, and in those in which a state is involved, the Supreme Court shall exercise original jurisdiction. In the other cases mentioned above, the Supreme Court will have jurisdiction in the level of appeal, ruling on both the facts and the law, observing the exceptions and rules that Congress establishes.

Desta maneira, o Judiciary Act de 1789 teria previsto uma competência recursal à SCOTUS para processar e julgar o mandamus, onde a Constituição declarou que a jurisdição deveria ser originária (MENDES; BRANCO, 2018, p. 52).

Por óbvio, a jurisdição recursal pressupõe a reforma de uma decisão anteriormente proferida por outro órgão do Poder Judiciário, não sendo possível criar uma hipótese recursal de forma inicial, sob o pretexto de estar sendo exercida competência recursal.

Nestes termos, os requerentes estariam movendo uma ação originária para obtenção dos termos de nomeação, o que não seria afeto propriamente à competência recursal, mas, ao revés, à competência originária, cuja hipótese não se encontra contemplada pela CEUA, tendo em vista que a competência originária da SCOTUS, prevista na mesma Constituição, não poderia ser alargada por lei ordinária, conforme se infere do seguinte trecho do voto de John Marshall:

[...] O critério essencial da jurisdição recursal é o de que ela revê e corrige os procedimentos numa causa já instalada, e não que ela crie a causa. Ainda que um mandamus seja dirigido às cortes, para obrigar um oficial a entregar determinado documento, trata-se da mesma coisa que mover uma ação originária para obter o documento e, portanto, parece pertencer não à jurisdição recursal, mas à originária. Nem é necessário em tal caso conferir competência à corte para exercer jurisdição recursal. A autoridade, portanto, conferida à Suprema Corte, pelo Judiciary Act de 1789, para expedir ordens mandamentais contra oficiais públicos, não parecer ter respaldo na constituição; e se torna necessário investigar, se uma jurisdição assim conferida pode ser exercida [...] (KLAUTAU FILHO, acesso em: 4 set. 2019).

Infere-se que a questão da lei ordinária em choque com a Constituição, na óptica de John Marshall, seria uma questão que demandaria o reconhecimento de certos princípios, dentro eles o direito originário do povo estabelecer princípios aptos a conduzir à sua própria felicidade. 
Ora, partindo dessa premissa, seria da natureza das coisas reconhecer que a Constituição consubstancia-se na lei superior, direito supremo, imutável por meios ordinários e usado como fundamento jusnaturalista pelo Chefe de Justiça, John Marshall, para fundamentar a supremacia constitucional (BASTOS, 2009, p. 59).

Nesta senda, a nulidade absoluta decorrente do ato legislativo, em contraste com a CEUA, também é pontuada do voto do Chefe de Justiça, Jonh Marshall, apesar disso o ato normativo contrário à Constituição seria nulo, pelo que os efeitos eventualmente produzidos por um ato inconstitucional deveriam ser desconstituídos pela decisão de inconstitucionalidade (BASTOS, 2009, p. 159).

Do exposto, pode ser concluído que a SCOTUS não teria competência para processar e julgar o mandamus, face à inconstitucionalidade apontada, motivo porque os termos de nomeação não poderiam ser entregues aos requerentes.

Cabe frisar, que o trecho final do voto esclarece o próprio fundamento do controle de constitucionalidade estadunidense, já que adota a fraseologia particularmente utilizada na Constituição dos EUA que adviria do princípio de que uma lei em choque com a Constituição resta nula (BASTOS, 2009, p. 159).

Isso, o que possibilita concluir que o decisum arrimava-se mais em princípios do que, no direito escrito oriundo da CEUA. Tais princípios seriam encontrados na natureza das coisas e na razão (BASTOS, 2009, p. 59).

Passo a expor, o segundo decisum oriundo da SCOTUS cujo objeto fora a declaração de inconstitucionalidade de uma lei federal (BASTOS, 2009, p. 61).

\section{O PRECEDENTE DRED SCOTT V. SANDFORD (1857)}

Na sequência, cabe destacar, a pretensão marcadamente conservadora do modelo de judicial review norte-americano. De fato, não havia uma noção de proteção aos direitos de minorias, como se pode notar do teor do precedente representado pelo caso Dred Scott contra Sandford (1857).

Com efeito, no ano de 1834, Dred Scott, um escravo pertencente a Emerson, cirurgião do exército, fora levado para Illinois. No entanto, mais tarde, Dred Scott fora conduzido ao Fort Snelling, no território de Louisiana, uma área onde a escravidão era proibida pelo 
Compromisso do Missouri, legislação federal proibitiva da escravatura nos novos territórios federais.

Apesar disso, tendo sido transferido de volta ao Missouri, Dred Scott ingressara com uma ação na Corte do Circuito $^{3}$ com o escopo de obter sua liberdade, baseando sua ação na argumentação de que a residência em um território livre conferia liberdade. Todavia, tal demanda restou improvida, levando-o a recorrer à SCOTUS (BASTOS, 2009, p. 61).

Cabe salientar, que o voto apresentado pelo Chefe de Justiça, Juiz Roger B. Taney, representando a maioria dos juízes da Supreme Court of the United States (SCOTUS), fora justificado em forte vertente originalista, com este teor ${ }^{4}$ :

[...] The question is simply this: can a black man, whose ancestors were imported into
this country, and sold as slaves, become a member of the political community formed
and brought into existence by the United States Constitution and, as such, become the
holder of all rights and privileges and immunities, guaranteed (sic) by this instrument
to the citizen? One of the rights is the privilege of suing a United States court in the
cases specified in the Constitution. We think ... [black people] ... are not included, and
were not intended to be included, under the word's "citizens" in the Constitution, and
therefore cannot claim any of the rights and privileges that this instrument provides
and assures citizens of the United States. On the contrary, they were at that time
considered as subordinates and a lower class of beings, who were subjugated by the
dominant race and, emancipated or not, still remained subject to their authority, and
had no rights or privileges, but as those who held power and the Government can
choose to grant them. It is not for the court to decide on justice or injustice, the policy,
of these laws.

Por conseguinte, o voto proferido procurava separar a jurisdição constitucional da política. Havia a tentativa de diferenciação entre jurisdição e política. Para tanto, utilizou-se da noção de intenção original dos legisladores constituintes, o que vedaria a apreciação do pedido.

Nesta sequência, a análise das premissas do originalismo, quais sejam, o textualismo e o intencionalismo, aplicados na CEUA, mostram que o texto constitucional não mencionou em um único e claro comando acerca da escravidão, razão pela qual, debitou-se ao texto constitucional, uma conclusão que não decorreria explicitamente de seu texto.

De fato, tais razões não poderiam ser extraídas do texto constitucional considerado isoladamente, sob pena de petição de princípio (DWORKIN, 2005, p. 46). Não podendo, tal inferência, ser extraída da moralidade política ante a controvérsia acerca da criação de uma nação livre, cujo cidadão poderia ser escravo de uma outra pessoa.

\footnotetext{
${ }^{3}$ A organização do sistema judicial americano se assemelha a uma pirâmide, na base da qual estão os tribunais de primeira instância; logo acima estão os tribunais de apelação (Tribunal de Apelações dos EUA); na ponta do sistema, está a mais alta corte do país, a Suprema Corte. O modelo do tribunal federal é replicado como regra nos Estados Unidos, em um modelo triplo composto por tribunais de julgamento, tribunais de apelação intermediários e um tribunal de última instância (FINE, 2011, p. 33, 48).

4 UNITED STATES OF AMERICA. Supreme Court. Dred Scott v. Sandford, 1856. Disponível em: <https://supreme.justia.com/cases/federal/us/60/393/>. Acesso em: 28 jan. 2019.
} 
Neste sentido, a conclusão do voto proferido por Taney representou a invalidação do compromisso do Missouri, que proibia a escravidão nos territórios federais, fundamentando a nulidade no argumento de que o Congresso Nacional não possui atribuição para dispor sobre a matéria, já que ninguém poderia perder os seus bens sem o devido processo legal (BASTOS, 2009, p. 61).

Não obstante, não se poderia simplesmente dizer que a intenção dos que escreveram a Constituição seria aceitar que ela fosse lei suprema, isto porque, a questão giraria em torno da força da Constituição, bem como, a relevância das intenções que ela incorpora (DWORKIN, 2005, p. 47).

Lembrando-se que o originalismo, enquanto técnica hermenêutica, toma por base uma leitura textual da Constituição, além de pretender com as suas técnicas alcançar a intenção original dos elaboradores do texto constituinte (BREST, 1990, p. 227, 228).

Nestes termos, a linguagem comum e jurídica que compartilhamos estabelece a ligação entre os processos ou disposições mentais de uma pessoa e as suas intenções de maneira satisfatória para propósitos jurídicos (DWORKIN, 2005, p. 53).

Podemos notar, que a primeira dificuldade de tal conceito consiste na impropriedade da combinação de uma intenção individual com alguma intenção do grupo em geral. A rigor, não existe uma intenção original a ser descoberta, mas algo a ser criado (DWORKIN, 2005, p. $50,51)$.

Dessarte, a ideia de intenção original não é o início de uma teoria de revisão judicial, uma vez que (DWORKIN, 2005, p. 52, 53, 55, 56):

\footnotetext{
a) a intenção original é um conceito aberto e não existe determinação da melhor escolha;

b) não existe sequer conceito compartilhado sobre o que seja intenção individual;

c) não existe um conceito de intenção de grupo;

d) não existe uma convenção do que vem a ser intenção original.
}

Em consequência, é essencial que se conclua que a verdadeira revolução deveria ser empreendida pelo Poder Legislativo, como de fato ocorrera ante a aprovação da Décima Terceira e da Décima Quarta Emendas na CEUA, visto que o processo de legiferação e criação dos direitos possui como espaço próprio o Poder Legislativo (HABERMAS, 1997, p. 122).

Nesse seguimento, passa-se a esclarecer a origem da segregação racial nos E.U.A, mesmo após o fim da escravatura.

\section{O PRECEDENTE PLESSY V. FERGUSON (1896)}


Em primeiro lugar, devemos regressar ao dia 7 de junho de 1892, data em que Plessy pagou uma passagem de trem para viajar até Covington, no Estado de Louisiana.

Destaca-se que Plessy era cidadão, na proporção de sangue de sete oitavos caucasiano e um oitavo africano, o que lhe garantia a qualidade de cidadão americano da raça branca, segundo sua argumentação, motivo porque, ingressara no trem de passageiros, tomando assento em um vagão destinado as pessoas brancas.

Na sequência, o maquinista ordenou a desocupação do assento, não sendo tal pleito atendido por Plessy. Por conseguinte, a força pública foi requerida e acionada para prendê-lo, resultando o ato em uma acusação criminal.

Em virtude de violação à Décima Terceira Emenda e à Décima Quarta Emenda, Plessy teria apresentado um mandado de proibição interporto perante a Suprema Corte do Estado de Louisiana, de modo, a trancar a acusação criminal.

No entanto, o mandado restou improvido o que ocasionou o manejo de um certiorari dirigido à Supreme Court of the United States (SCOTUS).

O Justice Henry Brown apresentou manifestação pela Supreme Court of the United States (SCOTUS), analisando a questão à luz da Décima Terceira ${ }^{5}$ e da Décima Quarta Emenda ${ }^{6}$ a Constituição dos Estados Unidos da América, inicialmente, afirmou que:

"this case goes against the constitutionality of an act of the Louisiana General Assembly, which passed in 1890 , to supply separate wagons for the races of white and black people $[\ldots . .]^{\prime \prime}$.

Nessa manifestação enfatizou que:“[...] The constitutionality of this act is attacked based on the fact that it conflicts with both the Thirteenth Amendment to the Constitution, abolishing slavery, and the Fourteenth Amendment, [...]”. Em seguida afirma: "[...]That it does not conflict with the Thirteenth Amendment, which abolished slavery and involuntary servitude, except as punishment for crime, is too clear for argument $[\ldots]^{8}$.

\footnotetext{
${ }^{5}$ XIII Emenda - Seção 1: Não haverá, nos Estados Unidos ou em qualquer lugar sujeito à sua jurisdição, nem escravidão, nem trabalhos forçados, salvo como punição por um crime pelo qual o réu tenha sido devidamente condenado [...] (FINE, 2011, p. 148).

${ }^{6}$ XIV Emenda - Seção 1: Todas as pessoas nascidas ou naturalizadas nos Estados Unidos e sujeitas à sua jurisdição são cidadãs do país e do estado onde tiverem residência. Nenhum estado poderá fazer ou executar leis que restrinjam os privilégios ou as imunidades dos cidadãos dos Estados Unidos, nem privar qualquer pessoa de sua vida, liberdade ou bens sem processo legal, ou negar a qualquer pessoa sob sua jurisdição igual proteção das leis [...] (FINE, 2011, p. 149).

7 UNITED STATES OF AMERICA. Supreme Court. Plessy v. Ferguson, 1896. Disponível em: <https:///supreme.justia.com/cases/federal/us/163/537/case.html>. Acesso em: 29 jan. 2019.

8 UNITED STATES OF AMERICA. Supreme Court. Plessy v. Ferguson, 1896. Disponível em: <https:///supreme.justia.com/cases/federal/us/163/537/case.html>. Acesso em: 29 jan. 2019.
} 
Em análise circunstanciada, pode assegurar-se que a primeira constatação levada a efeito pela SCOTUS era a impertinência da argumentação em relação à violação da Décima Terceira Emenda, uma vez que não estava em questão um estado de sujeição, muito menos o controle do trabalho ou serviços de um homem em benefício do outro; não implicando a segregação em ausência de disposição em relação de uma pessoa em favor dela própria, de seus bens ou serviços.

Na sequência analítica, infere-se que segunda constatação da SCOTUS seria a de que a separação de pessoas negras e brancas em vagões de trens diferentes, não implicava em inferioridade de uma raça à outra, estando a distinção dentro do poder de polícia conferido ao Poder Legislativo, cujas distinções eram reconhecidas como válidas, porquanto, não haveria privação de direitos, não havendo privação de propriedade sem o devido processo legal, nem haveria uma negação da proteção da igualdade perante a lei, na forma da Décima Quarta Emenda.

Por certo, o historicismo e a força das tradições na interpretação das normas jurídicas são características do originalismo presentes no precedente Plessy contra Ferguson. O precedente legitimou a segregação racial, pela própria natureza das coisas, uma vez que a jurisdição constitucional não poderia, segundo o argumento do juiz Henry Brown, ser utilizada para igualar raças inerentemente desiguais.

Decerto, quando expressões como igualdade perante a lei está em questão, a única descrição plausível de intenção seria aquela pretensão de formular um conceito acerca da igualdade, ou concretamente a consagração de uma concepção particular desse conceito (DWORKIN, 2005, p. 66)

Por conta disso, não seria adequado uma formulação historicista do conceito, mas a escolha do enunciado a usar na elaboração de uma concepção de intenção constitucional. Por certo, os magistrados deveriam tornar decisões substantivas de moralidade política, não no lugar dos julgamentos feitos pelos constituintes, mas antes a serviço desses julgamentos (DWORKIN, 2005, p. 67).

Resumidamente, uma intenção constitucional não tem nenhuma interpretação natural estabelecida. Toda justificativa para interpretação, e, portanto, para o entendimento do que os constituintes pretenderam deve arrimar-se em uma teoria política, e não em alguma intenção original historicista, textualista ou intencionalista (DWORKIN, 2005, p. 77). 
Do exposto, pode ser concluído que tal decisum da SCOTUS apenas serviu para legalizar a segregação racial, criando cidadãos de segunda classe, de modo a consolidar violência injustificável contra a minoria afrodescendente.

\section{O PRECEDENTE BROW V. BOARD OF EDUCATION OF TOPEKA (1954)}

No caso Brown contra Board of Education of Topeka ${ }^{9}$, os queixosos eram crianças negras em idade escolar primária residentes na cidade de Topeka.

Os queixosos interpuseram uma ação no Tribunal Distrital do Kansas, para impedir a execução de um estatuto que permitia, mas não exigia, nas cidades de mais de 15.000 habitantes, manter instalações escolares separadas para alunos negros e brancos.

Esta norma era denominada de Estatuto Geral do Kansas (Kan. Gen. Stat. 72-1724, 1949), que, de acordo com essa autoridade, a Junta de Educação de Topeka decidiu estabelecer escolas primárias segregadoras, o que não era adotado por outras escolas públicas da comunidade, já que elas eram operadas em uma base não-segregada.

O Tribunal Distrital de três juízes reuniu-se entendendo que a segregação na educação pública tem um efeito prejudicial sobre as crianças negras, mas negou a pretensão pelo fato de as escolas negras e brancas seriam substancialmente iguais no que diz respeito a edifícios, transporte, currículos e qualificações dos professores. Daí a interposição de certiorari, o qual fora concedido.

O Chefe de Justiça Earl Warren apresentou manifestação pela Suprema Corte dos Estados Unidos, analisando a questão com base na Décima Quarta Emenda, mas rompendo com a interpretação originalista, trouxe dados fáticos e sociológicos como ratio decidendi determinantes para fundamentar a inconstitucionalidade da política segregacionista, com este teor:

[...] BROWN Vs. BOARD OF EDUCATION, 347 US 483 (1954). 347 US 483 BROWN ET AL. v. EDUCATION COUNCIL OF TOPEKA ET AL. UNITED STATES DISTRICT COURT APPEAL FOR KANSAS DISTRICT No. 1. Discussed on December 9, 1952. Reaffirmed on December 8, 1953. Decided on May 17, 1954. Segregation of white and black children in public schools of a state solely on the basis of race, according to state laws that allow or require such segregation, black children deny the equal protection of the laws guaranteed by the Fourteenth Amendment, even though the physical facilities and other 'tangible' factors of white and black schools can be the same. (a) The history of the Fourteenth Amendment is inconclusive as to

\footnotetext{
${ }^{9}$ UNITED STATES OF AMERICA. Supreme Court. Brown v. Board of Education. Washington, 1954. Disponível em: <http://www.sbdp.org.br/arquivos/material/98_Brown\%20v\%20Board\%20of\%20 Education\%20 e\%20Plessy\%20v\%20Ferguson.pdf >. Acesso em: 30 jan. 2019.
} 
the intended effect on public education. (b) The question raised in these cases must be determined, not on the basis of the conditions existing when the Fourteenth Amendment was adopted, but in light of the full development of public education and its place in American life across the nation $[\ldots]^{10}$.

O Justice Earl Warren apresentou manifestação pela Suprema Corte dos Estados Unidos, analisando a questão com foco na Décima Quarta Emenda, sobretudo pela perspectiva da igual proteção da lei, corolário do princípio da igualdade. A segregação racial fora reputada inconstitucional, por ferir o princípio do equal protection of the law, inserida na Constituição norte-americana pela Décima Quarta Emenda. Pela importância dos argumentos apresentados trago a colação o teor do voto proferido:

[...] MR. CHEF JUSTICE WARREN presented the Court's opinion: These cases come to us from the states of Kansas, South Carolina, Virginia and Delaware. They are based on different facts and different local conditions, but one question justifies their consideration together in this consolidated opinion. In each case, black minors, through their legal representatives, seek help from the courts in obtaining admission to public schools in their community on a non-segregated basis. In each instance, [347 US 483,488 ] they were denied admission to schools attended by white children under laws that require or permit segregation according to race. This segregation was accused of depriving the plaintiffs of equal protection of the laws under the Fourteenth Amendment. In each case, with the exception of the Delaware case, a federal district court of three judges denied the reparations to the plaintiffs, based on the so-called 'separate, but equal' doctrine announced by this Court in Plessy v. Ferguson, 163 US 537. Under this doctrine, equal treatment is granted when breeds are provided with substantially equal facilities, although these facilities are separate. In the Delaware Case, the Delaware Supreme Court adhered to this doctrine, but ordered the plaintiffs to be admitted to white schools because of the superiority of the schools $[\ldots]^{11}$.

Em síntese, a decisão referente ao precedente englobou:

a) proteção de direitos de grupo minoritário na sociedade norte - americana;

b) rompimento com a interpretação originalista da Constituição dos Estados Unidos;

c) utilização do princípio da igualdade, precisamente a igual proteção da lei, contido na Décima Quarta Emenda;

d) utilização de fatos cientificamente comprovados representados por estudos psicológicos demonstrativos dos efeitos deletérios da segregação racial no desenvolvimento educacional do grupo segregado;

e) leitura moral da Constituição, por intermédio do uso de argumentos de princípios e não de argumentos de política.

\footnotetext{
${ }^{10}$ UNITED STATES OF AMERICA. Supreme Court. Brown v. Board of Education. Washington, 1954. Disponível em: <http://www.sbdp.org.br/arquivos/material/98_Brown\%20v\%20Board\%\%20of\%20Education\% 20e\%20Plessy\%20v\%20Ferguson.pdf $>$. Acesso em: 30 jan. 2019.

${ }^{11}$ UNITED STATES OF AMERICA. Supreme Court. Brown v. Board of Education. Washington, 1954. Disponível em: <http://www.sbdp.org.br/arquivos/material/98_Brown\%20v\%20Board\%20of\%20Education\%20 e\%20Plessy\%20v\%20Ferguson.pdf>. Acesso em: 30 jan. 2019.
} 
Primordialmente, o direito seria uma prática interpretativa, isto porque o seu significado como prática social dependeria necessariamente das condições de verdade das práticas argumentativas que o constituem. Desta maneira, o direito seria um conceito controvertido, contestado, melhor dizendo, disputado (DWORKIN, 2010, p. 17).

Neste sentido, o direito seria adjetivado como uma prática argumentativa. Por tal perspectiva, na elaboração do conceito deve ser atribuído valor e propósito à prática, de modo a formular concepções sobre as condições de veracidade das afirmações particulares que as pessoas fazem no contexto da prática, à luz dos propósitos e valores especificados (DWORKIN, 2010, p. 19).

Nesta sequência, a interpretação acerca ao direito seria necessariamente construtiva, pois estaria ligada à questão de impor um propósito a um objeto ou prática, a fim de torná-la o melhor exemplo possível de forma ou do gênero aos quais se imagina que pertençam (DWORKIN, 2007, p. 63, 64).

Com efeito, o interpretativismo nos fornece um modelo metódico de interpretação. A rigor, haveria um método de interpretação para decisão judicial como aqueles envolvendo a interpretação da Constituição (Caso Brown) (DWORKIN, 2007, p. 20, 25, 29, 36).

Por conseguinte, o fundamento da pretensão dos queixosos no caso Brow dizia respeito à admissão de crianças negras em escolas com bases não segregadas, sob o fundamento de que a segregação racial privaria os menores do princípio do equal protection of the law, apto a violar a Décima Quarta Emenda.

A ratio decidendi do julgado no caso Brown fundamentou-se no argumento de inconstitucionalidade da legislação cuja base seria unicamente a vontade da maioria, o que nega a igualdade e viola a igual proteção da lei (DWORKIN, 2005, p. 99).

Vê-se que os princípios consistem em um padrão distinto das regras, cuja característica essencial seria a aptidão para resolução de casos difíceis, não previstos em lei, levando em consideração o seu conteúdo moral, sem olvidar o fato da desnecessidade de sua previsão expressa na legislação (DWORKIN, 2017, p. 36).

Em outros termos, o argumento da violação do princípio do equal protection of the law significava entender-se violado o princípio da igualdade, pelo simples fato de existirem escolas apartadas entre crianças brancas e crianças negras, não importando a existência de fatores tangíveis iguais, como edifícios, currículos, qualificações e salários de professores. 
É de salientar, que a segregação racial encontrava arrimo nas legislações estaduais, que por sua vez, faziam menção à doutrina do separado, mas igual, fruto do precedente Plessy contra Ferguson.

O voto do Chefe de Justiça Warren parte da premissa envolvendo a impertinência da interpretação originalista para o deslinde da questão, já que não seria possível estabelecer com algum grau de certeza, qual seria a intenção dos proponentes da Décima Quarta Emenda em relação à educação em escolas públicas, na exata medida em que na época não havia escolas públicas gratuitas para brancos e negros, tendo em vista que a educação era fomentada por escolas particulares, inacessíveis aos negros.

A rigor, o Chefe de Justiça Warren cria uma nova técnica hermenêutica, lastreada na interpretação de princípios constitucionais, de acordo com fatos e valores (que ele entendia) vigentes à época.

Por isso, a utilização de princípios aliados a fatos cientificamente comprovados representa uma nova técnica interpretativa do texto constitucional, bem sintetizada por Barroso (2018, p. 352):

[...] A norma, muitas vezes, traz apenas um início de solução, inscrito em um conceito indeterminado ou em um princípio. Os fatos, por sua vez, passam a fazer parte da normatividade, na medida em que só é possível construir a solução constitucionalmente adequada a partir dos elementos do caso concreto. E o intérprete, que se encontra na contingência de construir adequadamente a solução, torna-se coparticipante do processo de criação do Direito. [...] Há muitas situações em que não existe uma solução pré-pronta no Direito. A solução terá de ser construída argumentativamente, à luz dos elementos do caso concreto, dos parâmetros fixados na norma e de elementos externos ao Direito [...] (BARROSO, 2018, p. 352)

Dessarte, as bases da leitura moral da Constituição forma lançadas pelo precedente Brown contra Board of Education of Topeka e sistematizadas pela teoria de direitos de Ronald Dworkin, norteadora de uma vertente de revisão normativa centrada no Poder Judiciário, na figura do juiz filósofo Hércules, que se utilizaria, para tanto, de argumentos de princípio e não argumentos de política.

Ronald Dworkin sustenta a sua tese fundamentado na premissa de que os juízes não deveriam criar um novo direito às partes a quando da análise de um caso difícil. Os magistrados, por tal premissa, não seriam legisladores segundos ou delegados, não sendo atribuído a eles qualquer poder normativo (DWORKIN, 2017, p. 128, 129).

Na sequência, Dworkin esclarece que a afirmação em sentido contrário, no sentido dos magistrados terem atribuição normativa como se legisladores fossem, faz obliterar uma 
importante distinção a ser realizada entre argumento de princípio e de política (DWORKIN, 2017, p. 129, 130). Nestes termos:

a) o argumento de política fomentaria ou protegeria um objetivo da comunidade como um todo;

b) o argumento de princípio seria instituído com vista a respeitar ou garantir um direito de um indivíduo ou de um grupo.

Desta forma, a função de interpretação realizada pelo jurista seria assemelhada a uma obra coletiva, um romance em cadeia, escrito por vários autores, no entanto nunca concluído.

Em outros termos, caberia a cada jurista o papel de intérprete e de criador do romance, isto de forma simultânea, melhor dizendo, na medida em que interpreta o que já fora escrito, ele teria a função de continuar um novo capítulo do romance. Dessarte, tudo deveria guardar coerência e integridade com aquilo até então produzido (DWORKIN, 2007, p. 275).

Por isso, haveria uma dimensão de adequação e interpretação necessária para o desenrolar do romance. Por adequação entende-se que não se poderia escrever um novo capítulo, que não seria adotado por nenhum autor. Por interpretação entende-se que deveria ser escrito um novo capítulo que se ajustasse melhor a obra como um todo (DWORKIN, 2007, p. 277).

Neste sentido, existiria uma diferença entre interpretar e inventar.

Por certo, ao assegurar o dever do jurista de conhecer a obra produzida até então, Dworkin assegura uma ligação com o passado. Por outro lado, ao impor o dever de guardar coerência para escrever o novo capítulo, existe limitação para a produção futura do jurista (DWORKIN, 2007, p. 271).

Dworkin (2007, p. 271) conceitua a noção de integridade no Direito, nestes termos:

[...] Neste capítulo iremos desenvolver a terceira concepção do direito que apresentarei no capítulo III. O direito como integridade nega que as manifestações do direito sejam relatos factuais do convencionalismo, voltados para o passado, ou programas institucionais do pragmatismo jurídico, voltados para o futuro. Insiste em que as afirmações jurídicas são opiniões interpretativas que, por esse motivo, combinam elementos que se voltam tanto para o passado quanto para o futuro; interpretam a prática jurídica contemporânea como uma política em processo de desenvolvimento. Assim, o direito como integridade rejeita, por considerar inútil, a questão de se os juízes descobrem ou inventam o direito; sugere que só entendemos o raciocínio jurídico tendo em vista que os juízes fazem as duas coisas e nenhuma delas $[\ldots]$.

Desta maneira, não poderia haver uma simbiose ilegítima entre a interpretação principiológica com a utilização de parâmetros políticos para resolução dos casos difíceis, 
mascarando-se a criação de novos direitos, a pretexto de colmatar omissões, ambiguidades, lacunas no direito ou esclarecer o conteúdo dos princípios, inventando e não interpretando.

Por outro lado, a dimensão unicamente legislativa no precedente Brown contra Board of Education of Topeka, fora desconsiderada com base em argumentos fáticos e valorativos, demonstrando, como nos ensina Ronald Dworkin a existência de uma dimensão valorativa, tão importante quanto a dimensão fática (DWORKIN, 2007, 165).

Por outras palavras, no tocante aos desacordos, nós poderíamos iniciar pontuando a existência de níveis de divergência no direito. Na divergência empírica há discordância quanto à circunstância de fato. Na divergência teórica existe polarização acerca do que o direito é, sobre a questão de se o corpus do direito escrito e as decisões judiciais esgotam ou não os fundamentos pertinentes do direito (DWORKIN, 2007, 165).

O Chefe de justiça Warren, ante a não aplicação da técnica originalista, rememorou a interpretação dos próprios precedentes da Suprema Corte dos Estados Unidos em relação ao caso.

A interpretação dos precedentes da Suprema Corte demonstrava que, a princípio, o entendimento era no sentido de que qualquer discriminação contra negros violaria a Decima Quarta Emenda.

No entanto, o quadro mudou após o precedente Plessy contra Ferguson, estendendo-se o mesmo raciocínio daquele precedente ao campo da educação pública.

Desse modo, a questão deveria partir não da interpretação originalista ou muito menos da comparação dos fatores tangíveis, como edifícios, currículos, qualificações e salários de professores, mas do próprio efeito da segregação sobre a educação pública, prevalecendo, desta forma, valores intangíveis, demonstrados por intermédio de estudos psicológicos, contidos na Nota 11 do precedente.

Por conseguinte, o direito à educação seria um pressuposto à cidadania e deveria ser disponibilizado em igualdade de condições, fazendo com que a simples segregação racial, por si mesma, fosse entendida como algo comprometedor do livre desenvolvimento educacional dos negros, na exata medida em que eles seriam marcados com a inferioridade ínsita à separação, o que fora comprovado por meio dos estudos psicológicos, todos citados na Nota 11 do julgado, que demonstrariam esse efeito nocivo, motivo porque um fato comprovado, aliado a um princípio constitucional, mostrava-se relevante para declarar a inconstitucionalidade da legislação estadual, contrária a um princípio constitucional. 
Como resultado, a inovação do julgamento capitaneado por Warren diz respeito à sensibilidade dele não com fatores tangíveis, mas sim com fatores intangíveis, principalmente o sentimento de inferioridade decorrente da separação entre negros e brancos e seus efeitos nos corações e mentes da população apartada, o que, por via de consequência, negaria as mesmas oportunidades educacionais e violaria a igual proteção da lei.

Por isso, as crianças afrodescendentes teriam direito a escolas públicas integradas com crianças brancas, já que o sentimento de inferioridade delas, por conta da segregação, até então vigente, representaria um valor intangível apto a impedir e solapar ao princípio da igual proteção da lei contida no texto constitucional, especialmente na Décima Quarta Emenda.

A decisão de dessegregação levada a efeito no caso Brown Vs. Board of Education of Topeka desconsidera o originalismo como vertente interpretativa válida para resolução da controvérsia.

Neste sentido, o Tribunal deveria tomar decisões de princípio, não de política, de modo, a definir os direitos que as pessoas têm sob nosso sistema constitucional e não decisões sobre como se promover melhor o bem-estar geral (DWORKIN, 2005, p. 101).

Cabe destacar, a crítica de Dworkin (2007, p. 37) fundada no argumento de que a segregação racial seria inerentemente injusta e em desacordo com os princípios constitucionais. Nestes termos, o decisum da Suprema Corte dos Estados Unidos significa uma solução conciliatória, que não nega peremptoriamente a doutrina do separado mais igual, já que não pois fim a segregação racial de forma imediata, ante a fórmula utilizada no julgado, a saber, a dessegregação deveria ocorrer "a toda velocidade adequada" (DWORKIN, 2005, p. 37).

Cabe sublinhar, que o papel mais incisivo dos Tribunais seria justificado a partir do compromisso com a democracia deliberativa, principalmente em duas classes de litígio, quais sejam (SUNSTEIN, 2009, p. 183, 184):

a) o primeiro toca aos temas centrais para o processo democrático, cujos temas muitas das vezes possuem pouca probabilidade de resolução pelo processo legislativo regular;

b) o segundo toca aos temas afetos a grupos minoritários, alijados do processo legislativo normal e com reduzidas probabilidades de obter uma audiência legislativa justa.

Nesse sentido, a crítica de Dworkin (2007) mostra-se pertinente, isto porque, dez anos após a decisão do caso Brown, apenas 1,2\% das crianças negras no Sul frequentavam escolas integradas (SUNSTEIN, 2009, p. 188). 
Por consequência, não houve uma mudança social efetiva, por conta do decisum, representando ele, o início do movimento dos direitos civis, que culminou com o engajamento do Poder Legislativo e do Poder Executivo, na aprovação da Lei dos Direitos Civis de 1964, este sim, o verdadeiro marco do processo de integração racial (SUNSTEIN, 2009, p. 188), o que demonstra ser o processo de legiferação o verdadeiro originador de direitos (HABERMAS, 1997, p. 165).

\section{CONCLUSÃO}

A Suprema Corte dos Estados Unidos progrediu de uma perspectiva originalista para um horizonte interpretativista.

Por conseguinte, a pesquisa adentrou na tarefa de interpretação do texto constitucional a partir de uma leitura interpretativista, adaptando o texto constitucional às mudanças da sociedade, levando em consideração tanto fatores extrajurídicos como fatos e valores vigentes em determinada época, de modo a atualizar o sentido possível do texto constitucional, o que foi evidenciado na metodologia utilizada no precedente Brown versus Board of Education of Topeka (1954).

Assim sendo, houve uma evolução no próprio método de controle de constitucionalidade das leis, porquanto antes se buscava a intenção original do constituinte, no entanto hodiernamente, almeja-se controlar a constitucionalidade com fundamento nos princípios constitucionais.

Conclui-se, assim, que o precedente Brown contra Board of Education of Topeka considera como razão determinante para a procedência do pedido de dessegregação, os princípios contidos na Constituição dos Estados Unidos da América, aliado a fato cientificamente comprovado, representado pelos estudos psicológicos contidos na Nota 11, de modo, que Warren adota nova técnica hermenêutica, lastreada na interpretação de princípios constitucionais, de acordo com fatos e com valores vigente na época, técnica não originalista, aqui denominada de interpretativista.

\section{REFERÊNCIAS}


CONSTITUIÇÃO DOS ESTADOS UNIDOS DA AMÉRICA. Disponível em: $<$ http://www.uel.br/pessoal/jneto/gradua/historia/recdida/Constituicaoeuarecdidapessoaljnet o.pdf.>. Acessado em 16 dez. 2018.

BARROSO, Luís Roberto. Curso de Direito Constitucional contemporâneo: os conceitos fundamentais e a construção do novo modelo. São Paulo: Saraiva, 2018.

BASTOS, Elísio Augusto Velloso. A garantia jurisdicional da Constituição Brasileira: análise e propostas para seu aprimoramento. Rio de Janeiro: Forense; São Paulo: Método, 2009.

BREST, Paul. The Misconceived Quest for the original understanding. In interpreting the Constitution. The Debate over Original Intent. Rakove, Jack N. (edit), Boston: Northeastern University Press, 1990.

DWORKIN, Ronald. Uma Questão de princípio. Trad. Luís Carlos Borges. São Paulo: Martins Fontes, 2005.

2017.

. Levando os direitos a sério. Trad. Nelson Boeira. São Paulo: Martins Fontes,

2007.

. O Império do Direito. Trad. Jefferson Luiz Camargo. São Paulo: Martins Fontes, 2010.

A Justiça de Toga. Trad. Jefferson Luiz Camargo. São Paulo: Martins Fontes,

FINE, Toni M. Introdução ao Sistema Jurídico Anglo-Americano. São Paulo: Martins Fontes, 2011.

HABERMAS, Jurgen. Direito e democracia entre facticidade e validade, Volume I. Tradução Flávio Beno Siebeneichler. 2. Ed. Rio de Janeiro: Tempo Brasileiro, 1997.

MENDES, Gilmar Ferreira; BRANCO, Paulo Gustavo Gonet. Curso de direito constitucional. $13^{\mathrm{a}}$ ed. São Paulo: Saraiva, 2018.

KLAUTAU FILHO, Paulo. A primeira decisão sobre controle de constitucionalidade: Marbury vs Madison (1803). Disponível em: <http://www.esdc.com.br/seer/index.php/ rbdc/article/view/50/50>. Acesso em: 16 dez. 2018.

SUNSTEIN, Cass R. A Constituição Parcial. Tradutores: Manasses Teixeira Martins e Rafael Triginelli, Belo Horizontes, Del Rey, 2009. 
One case at a time: judicial minimalism on the Supreme Court. Cambridge: Harvard University Press, 1999.

UNITED STATES OF AMERICA. Supreme Court. Dred Scott v. Sandford, 1856. Disponível em: <https://supreme.justia.com/cases/federal/us/60/393/>. Acesso em: 28 jan. 2019.

Supreme Court. Plessy v. Ferguson, 1896. Disponível em: <https://supreme.justia.com/cases/federal/us/163/537/>. Acesso em: 29 jan. 2019.

Supreme Court. Brown v. Board of Education. Washington, 1954. Disponível em: <http://www.sbdp.org.br/arquivos/material/98_Brown\%20v\%20Board\%20of\%20 Education $\% 20 \mathrm{e} \% 20 \mathrm{Plessy} \% 20 \mathrm{v} \% 20 \mathrm{Ferguson} . \mathrm{pdf}>$. Acesso em: 30 jan. 2019. 